\title{
Exposure Assessment of Bacillus cereus in Street Vended Chicken Briyani- a Deli Food of South India
}

\author{
P. Selvan ${ }^{1} *$ and N.S. Preethi ${ }^{2}$ \\ ${ }^{1}$ Department of Food Safety and Quality Assurance, College of Food and Dairy Technology, \\ TANUVAS, Chennai- 600 052, India \\ ${ }^{2}$ Department of Food Science and Technology, Indian Institute of Food Processing \\ Technology, Thanjavur - 613 005, India
}

*Corresponding author

\section{A B S T R A C T}

\section{Keywords}

Chicken Briyani, Bacillus Cereus,

Exposure

Assessment, Street food

Article Info

Accepted:

20 November 2018

Available Online:

10 December 2018
In the present study, exposure assessment of Bacillus cereus associated with the consumption of street vended chicken briyani sold in Koduvalli village, Ellapuram block, Thiruvallur district, Tamil Nadu was assessed. Enumeration of B. cereus in chicken briyani was carried out using Hichrome Bacillus Agar, a chromogenic media by adopting pour plate technique. Data on frequency of consumption of chicken biryani by the residents were collected using a structured questionnaire. The results revealed that the Bacillus cereus count in street vended chicken briyani was ranged between 2.32 to $5.54 \mathrm{log} \mathrm{cfu} / \mathrm{g}$ of sample. The mean B. cereus count was $4.03 \mathrm{log} \mathrm{cfu} / \mathrm{g}$ of sample. Invariably, all the samples analyzed were contained $B$. cereus. Similarly, the consumption pattern showed that the people at the age group of 20-35, 35-60 and 60 and above were consumed about $450 \mathrm{~g}$ of chicken briyani during each serve. This clearly indicate their higher vulnerability of these age groups to diarrhoeal syndrome followed by children at the age group of 5-12 and 13-19 who consumed $300 \mathrm{~g}$ of chicken briyani during each serve.

\section{Introduction}

FAO defined street foods as ready-to-eat foods and beverages prepared and/or sold by vendors or hawkers especially in the streets and other similar places (Hanashiro et al., 2005). Urban population growth has stimulated a rise in the number of street food vendors in many cities throughout the world. Street food vending generates significant employment in urban areas, which is important in alleviating poverty, the major causative factor for food insecurity (Namugumya and Muyanja, 2012). Street foods are adopted because they are inexpensive, palatable and are conveniently sold wherever people congregate. The mobile street foods practice is one of the multiple survival strategies adopted by poor urban households to maintain and expand the base of subsistence incomes especially in the surge of economic crisis (Acho-chi, 2002). The contribution of street food vendors to the economies of developing countries has been 
vastly underestimated and neglected. In the Indonesian city of Bogor annual sales of street foods amount to US\$67 million (Winarno and Allain, 1991).

Street vendors are ubiquitous in Indian metropolises too. WEIGO reported that about 10 million people across the country make a living by selling foods on the streets and sidewalks. Further, the National Policy for Urban Street Vendors/Hawkers stated that street vendors constitute approximately $2 \%$ of the population of a metropolis. Mumbai alone is home to an estimated 250,000 street vendors.

According to FAO it has been estimated that Calcutta has approximately 130, 000 streetvending stalls. Approximately half the vendors are stationary and the rest are itinerant. All India Institute of Hygiene and Public Health conducted a survey in Calcutta which reported that as many as 33 percent of the consumers purchased street foods on a daily basis, while about 23 percent patronized the stalls one to four times per week (Chakravarty and Cainet, 1994) Consumers spent Rs 40 to Rs 400 per month on street foods, according to their income and tastes. In Sealdah, a place in Kolkata, 1 to 2 percent of the consumers spent between Rs 700 and Rs 1000 per month on street foods because these foods provided their total daily diet. On average, regular consumers spent Rs. 250 on street foods per month.

Although street vending provides a flexible link in economic supply chains, serving as a source of employment, entrepreneurship, revenue, tourist attraction and value addition to the economy, street foods are frequently implicated with food poisoning. People who patronize street food, have been reported to suffer from food borne diseases like diarrhoea, cholera, typhoid and food poisoning. A study revealed that the major sources contributing to microbial contamination of such foods are the place of preparation, utensils for cooking and serving, raw materials, time and temperature abuse of cooked foods and the personal hygiene of vendors. Several studies have revealed prevalence of microorganism belonging to the genera Bacillus, Staphylococcus, Clostridium, Vibrio, Campylobacter, Listeria and Salmonella in street foods (Rane, 2011).

Chicken biryani, a Prepare, Cook and Serve mixed buffet, is one among the famous street food vended in Tamil nadu. In the existing practice, the vendors prepare the briyani in one place and stall it in the other.

The buffet will be kept at room temperature in a large container for considerable period of time until sold out. Since chicken biryani is cereal based mixed buffet there is increased chance for possible presence of microbial contaminants especially B.cereus, a facultative spore forming anaerobe that produce exotoxin when appropriate number is reached.

Generally, foodborne illness by Bacillus cereus occurs due to survival of the bacterial endospores when food is improperly cooked. Cooking temperatures less than or equal to $100{ }^{\circ} \mathrm{C}\left(212^{\circ} \mathrm{F}\right)$ allow some $B$. cereus spores to survive. This problem is compounded when food is then improperly refrigerated, allowing the endospores to germinate. Germination and subsequent bacterial growth that usually occur between $10{ }^{\circ} \mathrm{C}$ and $50{ }^{\circ} \mathrm{C}$ results in production of toxins that leads to emetic (vomiting) syndrome (Singh et al., 2016).

Exposure analysis describes how an individual or population comes in contact with a contaminant, including quantification of the amount of contact across space and time. The present study attempts to assess the exposure of population that consume street vended chicken briyani to $B$. Cereus. 


\section{Materials and Methods}

A study to assess the exposure of consumer to Bacillus cereus from the street vended chicken briyani samples collected from various street vendors in and around Koduvalli village was carried out in the Department of Food and Industrial Microbiology, College of Food and Dairy Technology, Chennai during the period between March 2017 and Aug 2017.

\section{Collection of samples}

A total of 30 street vended chicken briyani samples were randomly collected at different times from different sources throughout the course of study to determine the quantum of B. cereus. The collected samples were brought in insulated, refrigerated containers to the Food and Industrial Microbiology laboratory and the enumeration of B. cereus was carried out immediately following standard conventional culture procedure.

\section{Chemicals, media, buffers and reagents}

All the chemicals used in the study were of analytical grade, from reputed national and international firms. The media (Hichrome bacillus agar - M1651,a chromogenic media)and supplement (Bacillus selective supplement - FD324)used for the specific growth of Bacillus cereus were obtained from Hi-media, Mumbai.

\section{Microbial analysis}

Five gram of each street vended chicken briyani sample was taken aseptically and homogenized with $45 \mathrm{ml}$ of 0.1 percent sterile peptone water, using stomacher to detain an initial dilution of $10^{-1}$. Serial tenfold dilution was made upto $10^{-5}$ in pre-sterilized tubes containing $9 \mathrm{ml}$ of 0.1 percent peptone water. The sample preparation and plating was carried out under aseptic condition in a laminar flow.

\section{B. cereus count}

$49.22 \mathrm{~g}$ of Hichrome Bacillus Agar was suspended in one litre of sterile distilled water and the $\mathrm{pH}$ was adjusted to $7.1 \pm 0.2$. Then, the media was sterilized by autoclaving. Prior to pouring the medium into the petridishes, $10 \mathrm{ml}$ of reconstituted Bacillus Selective Supplement (FD 324) was added to the medium and mixed well.

One millilitre of inoculums from each dilution was placed in identified petridishes. The steile molten, cooled and Bacillus selective supplement added medium was then poured into the petridishes and mixed thoroughly. The petridishes after solidification of the medium were incubated at $30^{\circ} \mathrm{C}$ for $48 \mathrm{~h}$. Light blue, large, flat colonies with blue centre were counted and expressed as log cfu/g of sample.

\section{Assessment of consumption pattern}

Consumer particulars like age and health status including consumption pattern during a year were collected using a structured questionnaire (Fig. 1).

\section{Results and Discussion}

A study to assess the exposure of consumers to $B$. cereus from street vended chicken briyani was analyzed. Accordingly, the quantum of $B$. cereus in chicken briyani samples was assessed. Similarly, the consumer particulars including consumption pattern also collected using the questionnaire. The results are presented hereunder with discussion.

\section{Bacillus cereus count}

The Bacillus cereus count in street vended chicken briyani was ranged between 2.32 to $5.54 \mathrm{log} \mathrm{cfu} / \mathrm{g}$ of sample. The mean B. cereus count was $4.03 \log \mathrm{cfu} / \mathrm{g}$ of sample. 
Fig.1 Structured questionnaire to assess consumption pattern of consumers

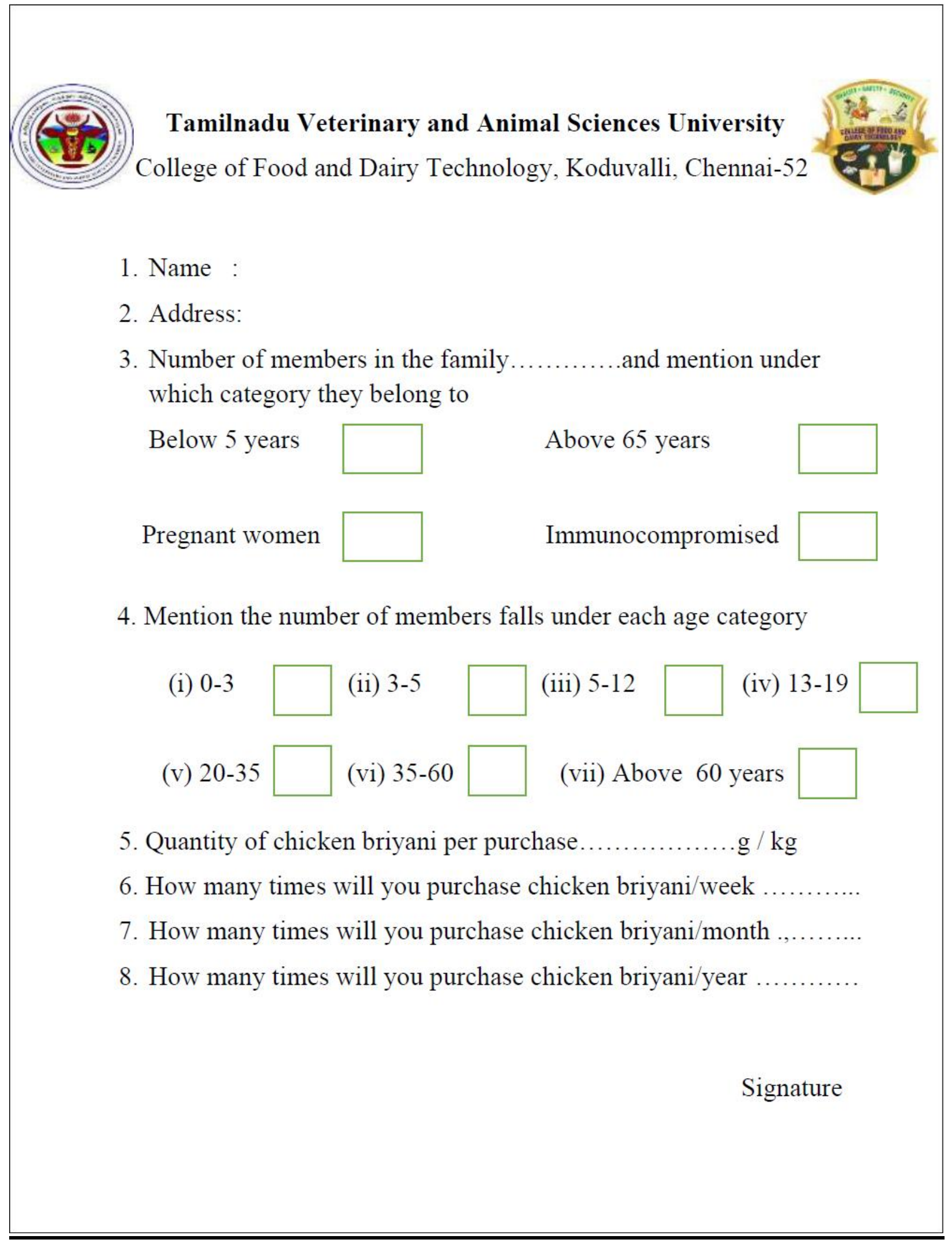


Invariably, all the samples analyzed were contained B. cereus. The results obtained in the present study is in accordance with the result of Manguiat and Fang, (2013) who studied microbial quality of chicken and pork based street vended foods from Laguna, Philippines and found that one of the sample contained unsatisfactory level (4 log cfu/g) of B.cereus. The result obtained in the present study might be attributed to poor handling practices during preparation and also to inadequate cooking that would have led to escape of some of the B. cereus spores.

\section{Consumption pattern}

A total of 30 consumers responded to the questionnaire. Pooled together the total numbers of family members were calculated as one hundred and sixteen. The maximum number of population fell in the age group of 20-35 (30.17\%) and 35-60 (29.31\%) followed by $13-19(13.79)$ and $5-13(12.93 \%)$. The percentage of population that falls under other age groups viz., 0-3, 3-5 and above 60 were $0.07 \%, 0.03 \%, 0.02 \%$, respectively. None of the consumer has reported presence of pregnant women or immunocompromised persons in their family. Further, it was observed that children in the age group of 0-3 and 3-5 were very rarely fed with the chicken briyani and that too very minuscule quantity whereas children in the age group of 5-12 and 13-19 were reported to consume a serve contains about $300 \mathrm{~g}$ of chicken briyani per week on one occasion. A serve of chicken briyani for the consumer belonging to the age group 20-35, 35-60 and 60 and above were about $450 \mathrm{~g}$.

\section{Exposure assessment}

The emetic intoxication occurs due to the ingestion of preformed cereulide toxin in the food and is generally produced when the $B$. cereus count exceeds $10^{5} \mathrm{cfu} / \mathrm{g}$. The toxin can withstand temperatures in excess of $120^{\circ} \mathrm{C}$ for 90 minutes and is not inactivated by reheating food. Further, the dose of enterotoxin required to produce human illness is relatively large. Similarly, the diarrhoeal syndrome is considered to be toxico-infection and is due to consumption of live $B$. cereus (at levels exceeding $10^{6} \mathrm{cfu} / \mathrm{g}$ ) and its heat- labile diarrhoeal enterotoxin. Large numbers of the bacteria are required to cause this illness (HPSC, 2012). In seven out of thirty (23.33\%) chicken briyani sample examined, the $B$. cereus count was about $10^{5} \log \mathrm{cfu} / \mathrm{g}$ of briyani at the point of consumption. The probabilities of inflicting food borne illness by these samples are relatively more compared to the rest of the chicken briyani samples. However, at this level of contamination, the possibility of occurrence of emetic syndrome is rare due to low or no toxin production. Conversely, the possibility of occurrence of diarrheal syndrome is relatively more and is closely related to the quantum of chicken briyani consumed. In the present study, the people at the age group of $20-35,35-60$ and 60 and above were consumed about $450 \mathrm{~g}$ of chicken briyani during each serve. This clearly indicate the higher vulnerability of these age groups to diarrhoeal syndrome followed by children at the age group of 5-12 and 13-19 who consumed $300 \mathrm{~g}$ of chicken briyani during each serve. However, other factors like virulence of the organism, immune status of consumer etc., will influence the occurrence of food poisoning in the individuals.

\section{References}

Hanashiro, A., Morita, M., Matte, G.R., Matte, M.H. and Torres, E.A.F.S. 2005.Microbiological quality of selected foods from a restricted area of Sao Paulo city, Brazil. Food Control 16: 439-444.

Namugumya, B.S. and Muyanja, C. 2012. 
Contribution of street foods to the dietary needs of street food vendors in Kampala, Jinja and Masaka districts, Uganda. Public Health Nutrition, Volume 15, Issue 8: 1503-1511.

Acho-Chi, C. 2002.The mobile street food service practice in the urban economy of Kumba, Cameroon. Singapore Journal of Tropical Geography, 23(2), $131-148$

Winarno, F.G. and Allain, A. 1991.Street foods in developing countries: lessons from Asia. From 'Food, Nutrition and Agriculture - 1 - Food for the Future'. Edited by -Albert, J.L., Tucker, R., Roland, N., Gigli, and Thompson, B.

Chakravarty, I. and Cainet, C. 1996. Street foods in Calcutta. Food Nutr. Agric., 17/18: 30-7.

Rane, S. 2011. Street Vended Food in
Developing World: Hazard Analyses. Indian J Microbiol 51(1):100-106.

Singh, N., Kumar, B., Kolli, M.K., Kumari, M, Mishra, A.K., 2016. Molecular docking studies of some novel thiophene carbohydrazide derivatives on enterotoxin of Bacillus cereus. International Journal of Current Pharmaceutical Research. Vol 8, Issue $3,59-63$.

Manguiat, L.S. and Fang, T.J., 2013. Microbiological quality of chicken- and pork-based street-vended foods from Taichung, Taiwan, and Laguna, Philippines. Food Microbiol. 2013, 36(1):57-62.

Health Protection Surveillance Centre, 2012. Infectious Intestinal Disease: Public Health \& Clinical Guidance. Pp. 19.

\section{How to cite this article:}

Selvan, P. and Preethi, N.S. 2018. Exposure Assessment of Bacillus cereus in Street Vended Chicken Briyani- A Deli Food of South India. Int.J.Curr.Microbiol.App.Sci. 7(12): 2894-2899. doi: https://doi.org/10.20546/ijcmas.2018.712.329 